\title{
Examining the safety, efficacy, and patient acceptability of inhaled loxapine for the acute treatment of agitation associated with schizophrenia or bipolar I disorder in adults
}

This article was published in the following Dove Press journal:

Neuropsychiatric Disease and Treatment

Justin Faden'

Leslie Citrome ${ }^{2}$

'Lewis Katz School of Medicine, Temple University, Philadelphia, PA 19125, USA; ${ }^{2}$ Psychiatry \& Behavioral Sciences, New York Medical College, Valhalla, NY 10595, USA
Correspondence: Leslie Citrome II Medical Park Drive, Suite 106, Pomona, NY 10970, USA

Tel + I 845362208 I

Email citrome@cnsconsultant.com

\begin{abstract}
Agitation is a common and serious symptom of bipolar mania and schizophrenia, and can be defined as excessive motor and verbal activity. If left unrecognized and untreated, agitation can evolve into aggression, resulting in potential patient and staff injury. An ideal treatment for agitation would have a rapid onset, cause calmness without sedation, and be tolerable, efficacious, and non-coercive, while managing the underlying condition. A novel approach for the treatment of agitation is inhaled loxapine. Inhaled loxapine is rapidly absorbed into the systemic circulation through the alveoli, resulting in a near immediate onset of action. The efficacy of inhaled loxapine was established in an extensive clinical development program that included persons with schizophrenia and bipolar mania. Additionally, inhaled loxapine has comparable efficacy to intramuscular ziprasidone, olanzapine, haloperidol, aripiprazole, and lorazepam, with the added benefit of being non-painful and non-traumatizing. Inhaled loxapine carries a bolded black box warning for bronchospasm, and as a result, in the US, requires enrollment in a Risk Evaluation and Mitigation Strategy program, and is contraindicated in those with pulmonary disease. Additionally, the use of inhaled loxapine can be associated with dysgeusia and throat irritation. Inhaled loxapine requires some degree of patient cooperation, and therefore may not be appropriate for all agitated patients.
\end{abstract}

Keywords: inhaled loxapine, agitation, schizophrenia, bipolar disorder, mania, antipsychotic

\section{Introduction}

Agitation is a heterogeneous and multifactorial syndrome with varying causations, definitions, and displays, and accounts for nearly 1.7 million annual visits to the emergency department in the United States. ${ }^{1}$ Agitation can be seen in persons with acute bipolar mania and acute exacerbations of schizophrenia, particularly in emergency department settings as well as during acute hospitalizations. ${ }^{2}$

Broadly, agitation can be defined as abnormal and excessive motor and verbal activity. $^{3}$ When agitation evolves into aggression, it can result in patient and staff injury, and should be considered a medical and psychiatric emergency. ${ }^{4}$

This review will focus on one option for the treatment of agitation: inhaled loxapine. After a brief overview of pharmacotherapeutic principles, including that concerning oral and parenteral formulations, inhaled loxapine is discussed in detail. A literature search was conducted 8 October 2018 using the US National Library of 
Medicine's PubMed.gov resource (https://www.ncbi.nlm. nih.gov/pubmed/) using the words "inhaled loxapine", "staccato loxapine", and "agitation AND loxapine". Only full text articles were considered and there were no other filters. The search yielded a total of 144 results, and after eliminating duplicates, 89 citations were identified and reviewed by the authors for applicability.

\section{Pharmacotherapeutic principles}

Pharmacologic guidelines and algorithms for the treatment of agitation are numerous and constantly evolving. ${ }^{5}$ Pharmacologic treatment options are classically broken down into three options: oral and sublingual, intramuscular, and intravenous medications (Table 1 ) ${ }^{6}$ A fourth more recent option consists of inhaled medications. Pharmacologic options primarily consist of two different classes of medications; benzodiazepines and antipsychotics. For a medication to be utilized for the treatment of agitation, it needs to have a rapid onset of action, induce calmness without excessive sedation, be safe and tolerable, and be predictably efficacious in reducing agitation.

\section{Oral medications}

Oral medications have the benefit of being non-invasive and can be easily administered. However, oral administration by swallowing has the slowest onset of action and providers need to be cognizant of patients "cheeking" (taking but not swallowing) or otherwise diverting the medications. ${ }^{7,8}$ Liquid and oral disintegrating formulations of several antipsychotics and benzodiazepines have been developed, although not all remain commercially available. These options do not improve time to onset of action as these medications disintegrate in the saliva and must still be swallowed. ${ }^{9}$ An option that circumvents this is sublingual asenapine, which is absorbed in the oral mucosa and appears efficacious in reducing agitation as evidenced in a randomized placebo-controlled clinical trial. $^{10}$

\section{Intramuscular treatment options}

By entering the systemic circulation through the muscle's vasculature, intramuscular formulations provide faster absorption, bioavailability, and a more rapid onset of action when compared with oral medications. ${ }^{8,11,12}$ However, intramuscular administration of medications can lead to a higher incidence of adverse events with enduring consequences; for example, acute dystonia with haloperidol can negatively affect a patient's willingness to take antipsychotic medications in the future. ${ }^{8}$ Intramuscular benzodiazepines, such as lorazepam and diazepam, can also cause respiratory depression, especially in those with lung disease or sleep apnea. Injections of medications can be considered by some as coercive and invasive, reducing patient autonomy and damaging the doctor-patient therapeutic relationship. ${ }^{5}$ On a practical standpoint, the process of administering an injection in a person refusing medication places health care providers at increased risk of being assaulted as well as experiencing needlestick injuries. ${ }^{8}$

\section{Inhaled medications: loxapine}

Inhalation of medications allows for the potential of rapid absorption and thus the rapid onset of action. Inhaled loxapine was approved in 2012 by the US Food and Drug Administration (FDA) for the treatment of agitation associated with schizophrenia or bipolar mania. ${ }^{13,14}$ Its use in the US is limited to a single dose of $10 \mathrm{mg}$ in a $24-\mathrm{hr}$ period. The clinical development program for inhaled loxapine included three randomized placebo-controlled clinical trials in adults: a Phase II trial in patients with schizophrenia, a Phase III trial in patients with schizophrenia, and a Phase III trial in patients with bipolar mania. ${ }^{15-17}$ Loxapine itself is a first-generation antipsychotic and has been commercially available for decades. ${ }^{14}$

This is a novel approach to the management of agitation. No other antipsychotic is currently available as an inhaled formulation.

\section{Inhaled loxapine delivery system}

Inhaled loxapine is delivered through a handheld, singleuse, breath-activated device. The delivery system is designed to quickly administer the aerosolized drug into the alveoli, leading to a rapid systemic effect. ${ }^{18} \mathrm{~A}$ breath sensor on the device detects a single inhalation, triggering a thermally generated condensation aerosol of a thin layer of the drug, free of excipients, or propellants. ${ }^{18}$ Purity of the emitted medication is greater than $99.5 \%$, and no special breathing or hand/breath coordination is required. ${ }^{18}$ The vaporization process takes $0.1 \mathrm{~s}$, and the drug then rapidly cools and condenses into aerosol particles 1-3.5 microns in diameter, allowing for deep lung penetration and fast systemic absorption in less than a second. ${ }^{19}$ Inhaled loxapine is rapidly absorbed and reaches peak plasma concentration in approximately $2 \mathrm{mins}$ (Tmax), with a maximum concentration of $312 \mathrm{ng} / \mathrm{mL}$ (Cmax), and a half-life of 8 hrs. ${ }^{20,21}$ Deposition of particles into the oropharyngeal region is estimated to be only 


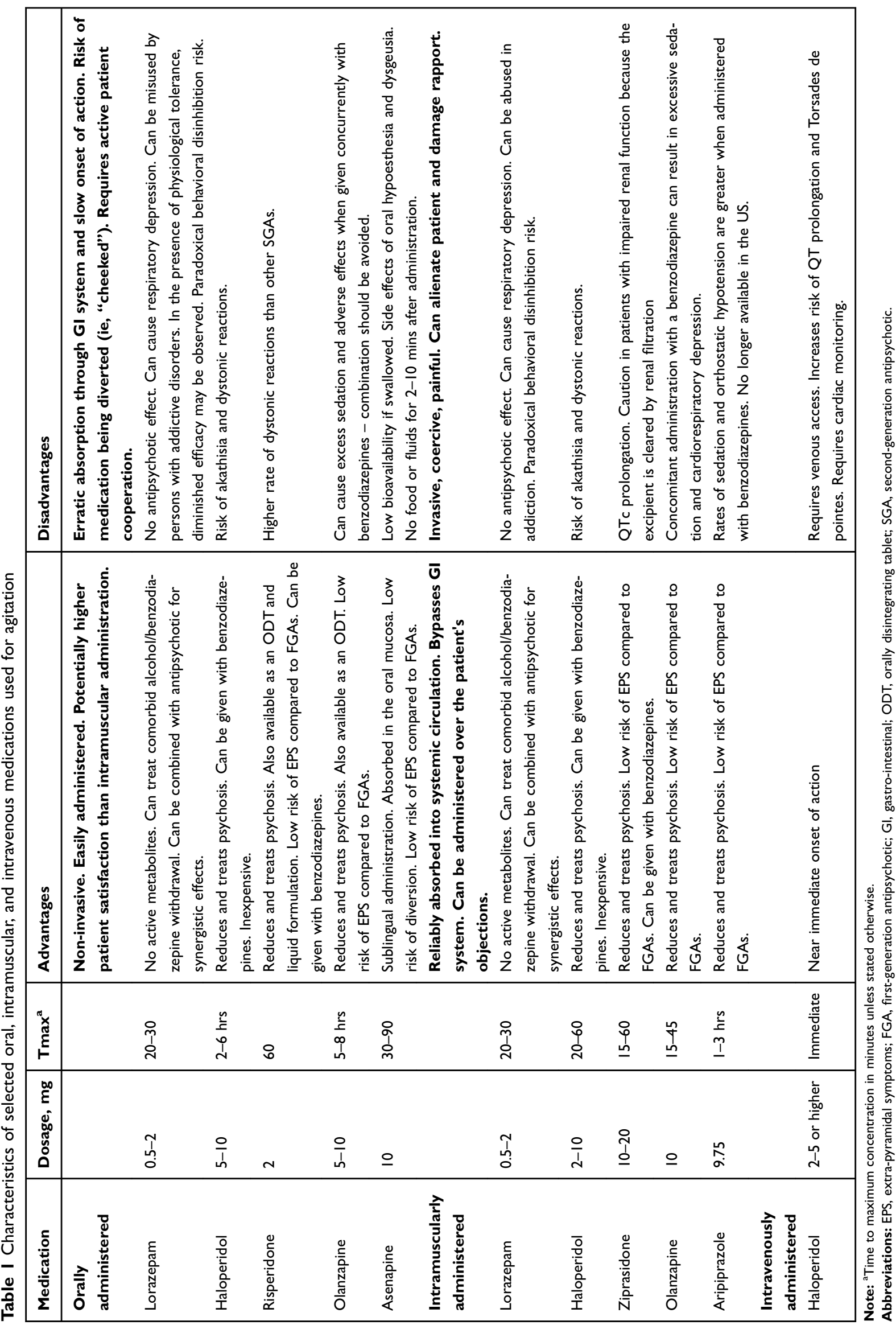


$11 \%$ of the emitted dose. ${ }^{22}$ Some degree of patient cooperation is necessary, potentially making inhaled loxapine unsuitable for patients with severe agitation.

\section{Inhaled loxapine pharmacology, mechanism of action (MOA), and pharmacokinetics}

Loxapine is a medium potency dibenzoxazepine antipsychotic medication that is structurally similar to clozapine. ${ }^{23}$ It is a post-synaptic antagonist at the $\mathrm{D} 2$ receptor, dissociating at an intermediate rate, as well as an antagonist at the serotonin 5-HT2A receptor. ${ }^{24,25}$ Based on human and animal studies, loxapine has a negligible affinity to glutamate N-methyl-D-aspartate (NMDA) receptors, unlike clozapine which may function as an NMDA receptor modulator. ${ }^{26,27}$ Other pharmacologic effects include antagonism at histaminergic $\mathrm{H} 1$, cholinergic $\mathrm{M} 1$, and adrenergic $\alpha 1$ receptors, which may be responsible for side effects including somnolence, anticholinergic effects, and orthostatic hypotension. ${ }^{3,28}$ Loxapine binds to the D4 receptor with higher affinity than to other dopaminergic receptors in human and animal models. ${ }^{26,29}$ Although it has a ratio of D2/D3 binding affinity that is similar to that of some atypical antipsychotic medications, a systematic Cochrane review assessing all randomized controlled trials comparing loxapine (in dosages up to $300 \mathrm{mg} /$ day) to other treatments for schizophrenia found the adverse effect profile of loxapine to be similar to that of other typical antipsychotic agents, and may cause a greater risk of extrapyramidal side effects than atypical antipsychotics. ${ }^{30}$ This may be attributed to the equipotent 5-HT/D2 affinity ratio. ${ }^{24,31}$ Although in vitro studies show loxapine affinity to 5HT2 receptors to be higher than its affinity to D2 receptors, in vivo human and animal studies have not supported this. ${ }^{24,32,33}$ Loxapine is metabolized to its primary $\mathrm{N}$-demethylated metabolite amoxapine, a tricyclic antidepressant, and via hydroxylation to 7-OH loxapine. ${ }^{34}$ In animal studies, the 7-OH loxapine metabolite has a fivefold higher affinity for the D2 receptor compared with loxapine, and thus it may contribute to the clinical effect of the drug as well as altering the 5-HT/D2 affinity ratio. ${ }^{20}$ However, inhaled loxapine has been shown to have a lower incidence of extrapyramidal symptoms (EPS) than oral loxapine due to lower levels of 7-OH reaching the striatum in rat brains, as well as possibly due to a lower dose exposure than in patients receiving ongoing oral treatment. $^{35}$

\section{Efficacy}

The efficacy of inhaled loxapine for the treatment of agitation associated with bipolar disorder and schizophrenia has been established in a Phase II study and two Phase III Studies (Table 2). Patients $\geq 65$ years of age were excluded from the studies. The study designs for each study were similar, with a primary efficacy endpoint being change from baseline on the Positive and Negative Syndrome Scale-Excited Component (PANSS-EC) after 2 hrs. Secondary endpoints included: (1) Clinical Global Impressions-Improvement Scale (CGI-I) score $2 \mathrm{hrs}$ after receiving study medication, (2) time to rescue medication (intramuscular lorazepam), (3) changes in PANSSEC measured 10, 20, 30, 45, 90, and 120 mins, as well as 4 and $24 \mathrm{hrs}$, after receiving study medication. For safety purposes, the Agitation-Calmness Evaluation Scale (Phase III studies) or Behavioral Agitation Rating Scale (Phase II study) was administered. In the Phase II study, participants were restricted to receiving only one dose of inhaled loxapine, however, in both Phase III trials, participants could receive up to three doses in the case of persistent or recurrent agitation over a $24-\mathrm{hr}$ period. In the Phase III studies, rescue lorazepam could be used after dose 2 and patients who received lorazepam rescue medication did not receive additional loxapine.

In the randomized, double-blind, placebo-controlled Phase II study, investigators randomized 129 agitated patients with schizophrenia or schizoaffective disorder to receive either inhaled loxapine $5 \mathrm{mg}, 10 \mathrm{mg}$, or placebo. ${ }^{15}$ Both inhaled loxapine 5 and $10 \mathrm{mg}$ resulted in a greater reduction in PANSS-EC scores compared to placebo, though only the $10 \mathrm{mg}$ dosage achieved statistical significance ( $p$-values 0.088 and 0.002 , respectively). Secondary endpoints revealed that inhaled loxapine $10 \mathrm{mg}$ statistically separated from placebo 20 mins after drug administration ( $p \leq 0.05$ ), whereas inhaled loxapine $5 \mathrm{mg}$ failed to statistically diverge, suggesting a dose-response relationship. After 2 hrs, there was a statistically significant improvement in CGI-I for both inhaled loxapine 10 $(p=0.0003)$ and $5 \mathrm{mg}(p=0.0067)$ compared to placebo. Time to rescue medication demonstrated advantages for both inhaled loxapine 5 and $10 \mathrm{mg}$ vs placebo.

Two Phase III studies were completed; one included agitated patients with schizophrenia, ${ }^{16}$ and another agitated patients with bipolar mania. ${ }^{17}$ Both studies were randomized, double-blind, multi-site, placebo-controlled, parallel-group trials. In the schizophrenia trial, a total of 344 patients were randomized to receive inhaled loxapine $5 \mathrm{mg}, 10 \mathrm{mg}$, or placebo. ${ }^{16}$ Both loxapine 5 and $10 \mathrm{mg}$ 


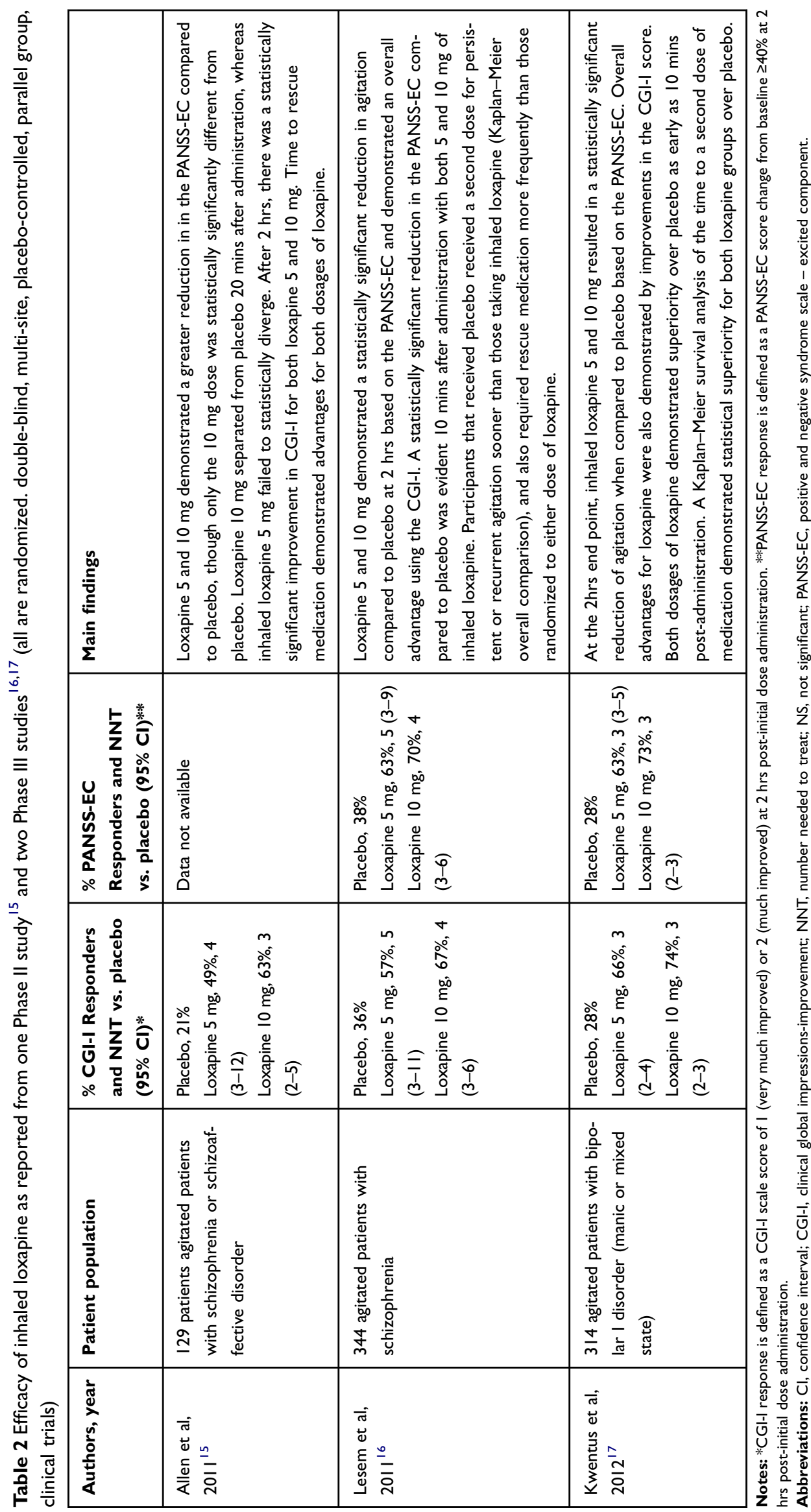


were superior to placebo in reducing agitation as measured by change in the PANSS-EC score at $2 \mathrm{hrs}(p=0.0004$ and $p<0.0001$, respectively). Reduced PANSS-EC scores relative to placebo were evident 10 mins after dosage (the first time point after administration where this assessment took place) with both 5 and $10 \mathrm{mg}$ of loxapine ( $p=0.0003$ and $p<0.0001$, respectively). The CGI-I score $2 \mathrm{hrs}$ after dosage demonstrated a statistically significant improvement for both loxapine $5 \mathrm{mg}(p=0.0015)$ and $10 \mathrm{mg}$ $(p<0.0001)$ dosages compared with inhaled placebo. Additionally, participants that received placebo required an additional dose for persistent or recurrent agitation sooner than those taking inhaled loxapine. A KaplanMeier survival analysis of the time to a second dose showed statistical superiority for loxapine $10 \mathrm{mg}$ over placebo $(p=0.0076$ ), whereas loxapine $5 \mathrm{mg}$ showed a numerical superiority that was not significant ( $p=0.115$ ). Participants receiving intramuscular lorazepam were $5 \%, 6 \%$, and $16 \%$ for those randomized to loxapine $10 \mathrm{mg}$, loxapine $5 \mathrm{mg}$, and placebo, respectively. ${ }^{3}$ The second Phase III study involved 314 agitated patients with bipolar disorder. ${ }^{17}$ Patients were randomized to receive inhaled loxapine $5 \mathrm{mg}, 10 \mathrm{mg}$, or placebo. At the 2-hr end point, inhaled loxapine 10 and $5 \mathrm{mg}$ resulted in a significant reduction of agitation when compared to placebo $(p<0.0001)$ based on the PANSS-EC score. Both dosage strengths of loxapine demonstrated superiority over placebo as early as 10 mins post-inhalation. The CGI-I score for both loxapine groups statistically separated from placebo at the 2 -hr endpoint $(p<0.0001)$. A Kaplan-Meier survival analysis of the time to the second dose of inhaled study drug showed statistical superiority for both loxapine groups over placebo ( $10 \mathrm{mg}, p<0.0001,5 \mathrm{mg}, p=0.0058$ ). Proportions of patients receiving intramuscular lorazepam were $9 \%, 9 \%$, and $21 \%$ for those randomized to loxapine $10 \mathrm{mg}$, loxapine $5 \mathrm{mg}$, and placebo, respectively.

An additional set of analyses of the data from the Phase III studies examined the percentage of patients achieving clinical response (defined as a reduction of $\geq 40 \%$ in PANSS-EC score) and also assessed changes in the five individual items of the PANSS-EC. ${ }^{36}$ Response was observed in approximately $20 \%$ of the patients with schizophrenia and bipolar disorder 10 mins after receiving inhaled loxapine in both 5 and $10 \mathrm{mg}$ doses. Response rate continued to improve over time until 90-120 mins post-inhalation where approximately $70 \%$ in the $10 \mathrm{mg}$ loxapine group for both schizophrenia and bipolar disorder were categorized as responders. Additionally, in both studies, there were statistically significant reductions in all five PANSS-EC items at the 2-hr post-administration time point $(p<0.05)$.

The number needed to treat (NNT) to achieve $\geq 40 \%$ reduction from baseline on the PANSS-EC at $2 \mathrm{hrs}$ for inhaled loxapine 10 and $5 \mathrm{mg}$ vs placebo for agitation associated with bipolar disorder is 3 and 3, respectively, and for agitation associated with schizophrenia, 4 and 5, respectively. Pooling the results, the NNT vs placebo for loxapine $5 \mathrm{mg}$ was $4(95 \% \mathrm{CI} 3-5)$ and the NNT for the $10 \mathrm{mg}$ dose was 3 (95\% CI 3-4). ${ }^{19}$ This compares well to NNT values for response for intramuscular ziprasidone (10 or $20 \mathrm{mg}$ vs $2 \mathrm{mg}$, NNT 3), olanzapine (10 mg vs placebo, NNT 3), haloperidol (6.5-7.5 mg vs placebo, NNT 4), lorazepam ( $2 \mathrm{mg}$ vs placebo, NNT 4), and aripiprazole (9.75 mg vs placebo, NNT 5). ${ }^{37}$

In a head-to-head, multi-site, open-label, assessorblind, randomized, active-controlled, parallel-group clinical trial, inhaled loxapine $10 \mathrm{mg}$ was compared with intramuscular aripiprazole $(9.75 \mathrm{mg})$ in acutely agitated patients with schizophrenia or bipolar I disorder. ${ }^{38}$ Three hundred and fifty-seven acutely agitated (CGI-Severity [CGI-S] score $\geq 4$ ) patients aged $18-65$ years were randomized (1:1) to receive inhaled loxapine or intramuscular aripiprazole. Patients received a maximum of two doses of study drug, with the second dose given at least $2 \mathrm{hrs}$ after the first for persistent or recurrent agitation. Rescue medication consisting of intramuscular lorazepam $2 \mathrm{mg}$ could be administered $\geq 20$ mins after the second dose of study medication if warranted. The primary efficacy endpoint was time to response, defined as a CGI-I score of 1 (very much improved) or 2 (much improved). Secondary endpoints included: (1) proportion of patients achieving CGI-I treatment response at 10,20,30,40,50,60,90, and 120 mins after dose one; (2) the number of patients who received one or two doses of study drug; (3) time to second dose of study medication; (4) the number of patients receiving rescue medication; (5) and satisfaction with treatment (evaluated with Treatment Satisfaction Questionnaire for Medication [TSQM]). Of the 357 patients, 297 were diagnosed with schizophrenia and 60 with bipolar disorder. In patients with schizophrenia, there was a statistically significant difference $(p=0.0028)$ in median time to respond for loxapine vs aripiprazole (50 mins [95\% CI 50.0-60.0 mins] vs $60 \mathrm{mins}$ [95\% CI 50.0-90.0 mins]). A similar trend was noted in patients with bipolar disorder, however, it did not reach statistical significance $(30 \mathrm{mins}$ [ $95 \% \mathrm{CI} \quad 20.0-60.0 \mathrm{mins}$ ] vs 50 
mins [ $95 \%$ CI $50.0-120.0$ mins] $)(p=0.06)$. Patients receiving inhaled loxapine responded more rapidly than those receiving intramuscular aripiprazole; at the 10 -min time point, $14 \%$ of the patients receiving loxapine achieved response compared to $3.9 \%$ of the patients receiving aripiprazole $(p=0.0009)$. This trend continued up to the 60 min time point, and at 120 -mins, $84.4 \%$ of the patients receiving loxapine showed response compared to $82.6 \%$ of the patients receiving aripiprazole. Few patients in each treatment group received dose two, and only one patient in the study received a rescue medication. Of note, shortacting injectable aripiprazole is no longer commercially available in the US.

In a retrospective chart review, pragmatic outcome measures, including the need for rescue medications, use of restraints, and time until achieving medical clearance after receiving medication, were assessed for patients in an emergency department. ${ }^{39}$ Subjects were patients that received antipsychotic medication for agitation associated with psychosis. Medications administered included inhaled loxapine, haloperidol, and ziprasidone. A total of 406 patients were identified and included in the study. Inhaled loxapine was compared to the combined results of ziprasidone and haloperidol (Table 3). After receiving inhaled loxapine or intramuscular haloperidol/ziprasidone, patients having received loxapine were medically cleared faster than those receiving other antipsychotics $(p<0.01)$, received fewer dosages of rescue medication consisting of benzodiazepines $(p<0.01)$, and were placed in physical restraints less frequently $(p<0.01)$.

\section{Safety}

\section{Adverse effects}

Tables 4 and 5 include a list of adverse events of interest that may be associated with inhaled loxapine. The adverse event occurring at a rate of $\geq 5 \%$ and $\geq 2$-times that observed with placebo is dysgeusia $(14.3 \%, 11.3 \%$, and $4.9 \%$ for loxapine $10 \mathrm{mg}, 5 \mathrm{mg}$, and placebo, respectively). The number needed to harm (NNH) for dysgeusia for inhaled loxapine vs placebo was 11 (95\% CI 7-23) for the $10 \mathrm{mg}$ dose and 16 (95\% CI 10-58) for the $5 \mathrm{mg}$ dose. ${ }^{3}$

EPS, including akathisia, were uncommon and statistically non-significant when compared to placebo, unlike what can be seen with intramuscular haloperidol. ${ }^{37}$ Inhaled loxapine does not prolong the QTc interval. ${ }^{21,28,40}$

\section{Does inhaled loxapine affect pulmonary function?}

Inhaled loxapine carries a black box warning for bronchospasm, and as a result, in the US, requires enrollment in a Risk Evaluation and Mitigation Strategy (REMS) program. ${ }^{28}$ As a consequence of the REMS program, administration of inhaled loxapine is restricted to health care facilities with access to supplies and personnel trained to manage acute bronchospasm, and have access to a short-acting bronchodilator (ie, albuterol). Similarly, patients with a diagnosis of asthma, chronic obstructive

Table 3 Efficacy of inhaled loxapine compared to other antipsychotics administered in an emergency department for agitation associated with psychosis, as measured by pragmatic outcomes ${ }^{48}$

\begin{tabular}{|c|c|c|c|}
\hline Medication, Total N=406 (\%) & \multirow{2}{*}{$\begin{array}{l}\text { Needing } \\
\text { restraints, Total } \\
\text { N=70 n (\%) }\end{array}$} & \multirow{2}{*}{$\begin{array}{l}\text { Median time (IQR) until medical clearance } \\
\text { after receiving first medication (hours) }\end{array}$} & \multirow{2}{*}{$\begin{array}{l}\text { Rescue medication (benzo- } \\
\text { diazepine), Total } \mathbf{N}=248 \\
\text { n (\%) }\end{array}$} \\
\hline Mode of administration, $\mathbf{n}(\%)$ & & & \\
\hline $\begin{array}{l}\text { Loxapine, } \mathrm{N}=54(\mathrm{I}) \\
\text { Inhaled, } \mathrm{N}=54\end{array}$ & $\mathrm{I}(\mathrm{I} .8)^{*}$ & $4.8(2.0-8.8)^{*}$ & $19(35.2)^{*}$ \\
\hline $\begin{array}{l}\text { All other antipsychotics, N=352 } \\
\text { Haloperidol, N=I27 (3I) } \\
\text { Oral } 9(7 . I) \\
\text { IM } 85(66.9) \\
\text { IV } 6(4.7) \\
\text { Missing } 27(21.3) \\
\text { Ziprasidone, N=225 (55) } \\
\text { Oral } 37(16.4) \\
\text { IM I46 (64.9) } \\
\text { Missing } 42(18.7)\end{array}$ & $69(19.8)^{*}$ & $7.2(3.8-13.3)^{*}$ & $229(65.1)^{*}$ \\
\hline
\end{tabular}

Note: ${ }^{*} p<0.01$, demonstrating significant difference between loxapine and other pooled antipsychotics.

Abbreviations: IM, intramuscular; IQR, interquartile range; IV, intravenous. 
Table 4 Adverse events as reported in Phase II and III trials comparing inhaled loxapine to placebo ${ }^{5}$

\begin{tabular}{|c|c|c|c|}
\hline \multirow[t]{2}{*}{$\begin{array}{l}\text { Adverse } \\
\text { event }\end{array}$} & $\begin{array}{l}\text { Placebo } \\
(N=263)\end{array}$ & $\begin{array}{l}\text { Loxapine } \\
5 \mathrm{mg}(\mathrm{N}=265)\end{array}$ & $\begin{array}{l}\text { Loxapine } \\
10 \mathrm{mg}(\mathrm{N}=259)\end{array}$ \\
\hline & N (\%) & N (\%) & N (\%) \\
\hline Dysgeusia & $13(4.9)$ & 30 (II.3) & $37(14.3)$ \\
\hline Somnolence & $25(9.5)$ & $32(12.1)$ & $31(12)$ \\
\hline Dizziness & $23(8.7)$ & $17(6.4)$ & $19(7.3)$ \\
\hline $\begin{array}{l}\text { Throat } \\
\text { irritation }\end{array}$ & I $(0.4)$ & $2(0.8)$ & $7(2.7)$ \\
\hline Any EPS & I $(0.4)$ & $5(1.9)$ & $4(1.5)$ \\
\hline Bronchospasm & $0(0)$ & $0(0)$ & $2(0.8)$ \\
\hline
\end{tabular}

Abbreviation: EPS, extrapyramidal symptoms.

Table 5 Adverse events as reported in a head-to-head trial comparing inhaled loxapine to intramuscular aripiprazole ${ }^{47}$

\begin{tabular}{|c|c|c|}
\hline \multirow[t]{2}{*}{$\begin{array}{l}\text { Adverse } \\
\text { event }\end{array}$} & $\begin{array}{l}\text { Loxapine } 10 \mathrm{mg} \\
(\mathrm{N}=179)\end{array}$ & $\begin{array}{l}\text { Aripiprazole } 9.75 \mathrm{mg} \\
(\mathrm{N}=178)\end{array}$ \\
\hline & N (\%) & N (\%) \\
\hline Dysgeusia & $22(12.3)$ & $0(0)$ \\
\hline Somnolence & $26(14.5)$ & $25(14.1)$ \\
\hline Dizziness & $4(2.2)$ & II (6.2) \\
\hline $\begin{array}{l}\text { Throat } \\
\text { irritation }\end{array}$ & $4(2.2)$ & $0(0)$ \\
\hline Any EPS & Not reported & Not reported \\
\hline Bronchospasm & $0(0)$ & $0(0)$ \\
\hline
\end{tabular}

Abbreviation: EPS, extrapyramidal symptoms.

pulmonary disease (COPD), any other lung disease associated with bronchospasm, or current acute respiratory symptoms (ie, wheezing), are contraindicated from receiving inhaled loxapine.

In the clinical trial program, including Phase II/III trials, one participant $(0.09 \%)$ out of 1095 study subjects without active airway disease required treatment with albuterol for bronchospasm. Cough was the most common airway adverse event (19/1095 subjects; $1.7 \%)$. In the Phase II/III clinical trials, approximately $87 \%$ of the patients were current or ex-smokers, yet bronchospasm was rare, occurring in $0 \%(0 / 263)$ of the placebo group and $0.8 \%(2 / 259)$ of the inhaled loxapine $10 \mathrm{mg}$ group, for a NNH of 130 (not significant). ${ }^{3}$ An important caveat is that severe asthmatics and very severe COPD patients were excluded from these studies, and thus the results may not reflect those in patients with more severe airway diseases.
To more fully appraise the potential of inhaled loxapine to adversely affect pulmonary function in persons with airway/lung disease, two distinct randomized, double-blind, parallel-arm, placebo-controlled trials were conducted comparing inhaled loxapine $10 \mathrm{mg}$ vs placebo in 52 patients with asthma and 53 patients with COPD. ${ }^{41}$ The primary outcome measure was spirometry results. The results showed that in subjects with asthma and COPD, inhaled loxapine causes a decrease in forced expiratory volume in $1 \mathrm{~s}$. In patients with asthma, there was also an increased risk of bronchospasm $(\mathrm{NNH}=5$ [3-23]). ${ }^{13}$ All airway adverse events in patients with asthma and COPD were mild or moderate in severity. Nonetheless, the "single digit" NNH results reinforce the need to avoid the use of inhaled loxapine in persons with active airway/lung disease.

\section{Patient acceptability}

Approximately two-thirds of patients recognize when they are becoming agitated and are also able to categorize and identify their triggers. ${ }^{42}$ Symptom recognition allows for intervention before agitation has time to escalate and intensify, resulting in better outcomes. As patients can often identify when they are becoming agitated, they can also often identify what best ameliorates agitation. To enhance the therapeutic alliance, patient's individual preferences and values should be taken into consideration. In a survey of 583 outpatients with schizophrenia or bipolar disorder who experienced episodes of agitation, the most commonly employed strategy for agitation was taking "as needed" medication, with high overall satisfaction for lessening agitation. ${ }^{42}$ A workgroup of 20 clinicians with experience in the clinical management of agitated patients met to identify a consensus statement for the ideal pharmacologic treatment of agitation. ${ }^{5}$ The group found inhaled loxapine to be the closest to an ideal treatment, with similar positive attributes to both intramuscular/intravenous medications (rapid onset of action), and oral/sublingual medications (non-invasive/non-coercive, advantageous tolerability, and high patient preference).

These patient satisfaction findings were assessed in the head-to-head comparison of inhaled loxapine vs intramuscular aripiprazole for the treatment of agitation described earlier. ${ }^{38}$ Study participants completed the TSQM 2 and 24 hrs after medication administration. ${ }^{43}$ Significantly more $(p=0.0012)$ patients in the inhaled loxapine group (53.8\%) than in the intramuscular aripiprazole group (36.4\%) were 
"very satisfied" or "extremely satisfied" with the treatment received.

In 168 patients with schizophrenia or bipolar disorder, health-related quality of life was surveyed using a time trade-off approach. ${ }^{44}$ Patients were asked about the impact of medication administration method for acute agitation, comparing oral, injection, and inhalation methods. Respondents considered treatment with inhaled medication to be preferable to receiving treatment with tablets or injections. Inhalation was the most valuable treatment and injection was the least valuable. The utility value, a measure of health status and quality of life, where 1 is perfect health and 0 is death, was 0.762 for inhalable treatment, 0.707 for injection, and 0.734 for tablet treatment, further reinforcing the potential advantage of inhaled formulations in the treatment of agitation.

\section{Cost}

Inhaled loxapine has a higher acquisition cost than the oral and intramuscular medications commonly used to treat agitation in psychiatric conditions. Based on a survey of five independent health care organizations in New York, New Jersey, and Pennsylvania conducted in 2019 March, the acquisition cost of inhaled loxapine $10 \mathrm{mg}$ is $\$ 140 /$ dose in the US, compared to much lower costs for alternative intramuscular medications (Table 6).

\section{Discussion}

An ideal medication for the treatment of agitation would be efficacious, tolerable, non-painful, and have a rapid onset of action. Inhaled loxapine plays a unique role due to its novel delivery system. Because of its administration through the deep lung, inhaled loxapine is rapidly

Table 6 Acquisition cost of inhaled loxapine compared to other frequently used medications for the treatment of agitation based on a survey of five independent health care organizations in Pennsylvania, New Jersey, and New York (by the authors, March 2019)

\begin{tabular}{|l|l|}
\hline Medication a $^{\text {a }}$ & $\begin{array}{l}\text { Mean cost in US dollars (range if } \\
\text { applicable) }\end{array}$ \\
\hline $\begin{array}{l}\text { Inhaled Loxapine } \\
10 \mathrm{mg}\end{array}$ & $\$ 140$ \\
Ziprasidone $20 \mathrm{mg}$ & $\$ 38.97(\$ 21.22-\$ 46.99)$ \\
Olanzapine 10 mg & $\$ 33.68(\$ 19.85-\$ 42.20)$ \\
Haloperidol $5 \mathrm{mg}$ & $\$ 0.83(\$ 0.57-\$ 1.18)$ \\
Haloperidol 10 mg & $\$ 1.67(\$ 1.14-\$ 2.35)$ \\
Lorazepam 2 mg & $\$ 0.90(\$ 0.46-\$ 1.79)$ \\
\hline
\end{tabular}

Note: ${ }^{a}$ Intramuscular unless otherwise specified. absorbed into the systemic circulation, resulting in a near immediate onset of action, with comparable efficacy to the intramuscular formulations of ziprasidone, olanzapine, haloperidol, aripiprazole, and lorazepam. The stigma and pain associated with the emergency use of short-acting intramuscular medication can be avoided with the use of inhaled loxapine. Thus, inhaled loxapine is a promising treatment for acute agitation secondary to schizophrenia and bipolar mania. Inhaled loxapine has also been utilized "off-label" in agitated patients with a borderline personality disorder, dual diagnosis (defined as concomitant psychiatric and substance use disorders), weaning from ventilation, electroconvulsive therapy pretreatment, and child and adolescent psychiatric conditions. ${ }^{45-49}$

However, like any treatment, there are drawbacks to inhaled loxapine. Loxapine has higher rates of dysgeusia and throat irritation when compared to placebo. As it is absorbed through the respiratory system, it is more likely to cause pulmonary adverse effects. Inhaled loxapine carries a black box warning for bronchospasm, and is contraindicated in those with pulmonary disease. The rate of bronchospasm (includes wheezing, cough, shortness of breath) is 37\% (19/52) in patients with COPD or asthma, but only $0.8 \%(2 / 259)$ in patients without pulmonary disease receiving $10 \mathrm{mg}$ loxapine. ${ }^{3,41}$ Of note, all airway adverse events in persons with schizophrenia or bipolar disorder were considered mild or moderate in severity, and smoking did not increase the risk of bronchospasm.

Inhaled loxapine may not be appropriate for some patients with severe levels of agitation because administering loxapine is a collaborative process, requiring patient cooperation. In persons already aggressive, or severely agitated and unable or unwilling to cooperate with an inhaled medication, intramuscular medication remains the first-line treatment.

\section{Conclusion}

Agitation is a clinical condition of paramount importance, and inhaled loxapine represents a new treatment option with a novel delivery system, resulting in the rapid onset of action without the need for injection. Patient satisfaction scores are high with comparable efficacy to existing treatment options. Inhaled loxapine has a prominent warning for bronchospasm and in the US requires a REMS program for use. In the US, inhaled loxapine is restricted to health care facilities with access to interventions and personnel trained to manage acute bronchospasm. Inhaled 
loxapine is not appropriate for all patients and is contraindicated in patients with a diagnosis of asthma, COPD, any other lung disease associated with bronchospasm, or any current acute respiratory symptoms. Additionally, as it requires patient cooperation to administer, it may not be appropriate for persons exhibiting severe levels of agitation. In considering the advantages and disadvantages, inhaled loxapine is a welcome addition to the armamentarium of pharmacologic options for patients with agitation secondary to schizophrenia or bipolar mania, and may be an ideal option for a subgroup of agitated patients.

\section{Disclosure}

Leslie Citrome was a consultant for and received personal fees from: Acadia, Alkermes, Allergan, Indivior, Intra-Cellular Therapeutics, Janssen, Lundbeck, Merck, Neurocrine, Noven, Osmotica, Otsuka, Pfizer, Shire, Sunovion, Takeda, Teva, and Vanda in the past 12 months. He was also a speaker for and received personal fees from: Acadia, Alkermes, Allergan, Janssen, Lundbeck, Merck, Neurocrine, Otsuka, Pfizer, Shire, Sunovion, Takeda, and Teva. He owns small number of shares of common stock from Bristol-Myers Squibb, Eli Lilly, J \& J, Merck, Pfizer and received royalties from Wiley as the Editor-in-Chief, International Journal of Clinical Practice, UpToDate as the reviewer, and Springer Healthcare (published a book), outside the submitted work. The authors report no other conflicts of interest in this work.

\section{References}

1. Allen MH, Currier GW. Use of restraints and pharmacotherapy in academic psychiatric emergency services. Gen Hosp Psychiatry. 2004;26(1):42-49. doi:10.1016/j.genhosppsych.2003.08.002

2. Garriga M, Pacchiarotti I, Kasper S, et al. Assessment and management of agitation in psychiatry: expert consensus. World J Biol Psychiatry. 2016;17(2):86-128. doi:10.3109/15622975.2015.1132007

3. Citrome L. Addressing the need for rapid treatment of agitation in schizophrenia and bipolar disorder: focus on inhaled loxapine as an alternative to injectable agents. Ther Clin Risk Manag. 2013;9:235-245. doi:10.2147/TCRM.S31484

4. Citrome L, Volavka J. Violent patients in the emergency setting. Psychiatr Clin North Am. 1999;22(4):789-801.

5. Martinez-Raga J, Amore M, Di Sciascio G, et al. 1st international experts' meeting on agitation: conclusions regarding the current and ideal management paradigm of agitation. Front Psychiatry. 2018;9:54. doi:10.3389/fpsyt.2018.00054

6. Wilson MP, Pepper D, Currier GW, Holloman GH Jr, Feifel D. The psychopharmacology of agitation: consensus statement of the american association for emergency psychiatry project Beta psychopharmacology workgroup. West J Emerg Med. 2012;13(1):26-34. doi:10.5811/westjem.2011.9.6866

7. Zimbroff DL, Marcus RN, Manos G, et al. Management of acute agitation in patients with bipolar disorder: efficacy and safety of intramuscular aripiprazole. J Clin Psychopharmacol. 2007;27 (2):171-176. doi:10.1097/JCP.0b13e318033bd5e
8. Zeller SL, Citrome L. Managing agitation associated with schizophrenia and bipolar disorder in the emergency setting. West J Emerg Med. 2016;17(2):165-172. doi:10.5811/westjem.2015.12.28763

9. Citrome L. Handbook of Treatment-resistant Schizophrenia. London, UK: Springer Healthcare; 2013.

10. Pratts M, Citrome L, Grant W, Leso L, Opler LA. A single-dose, randomized, double-blind, placebo-controlled trial of sublingual asenapine for acute agitation. Acta Psychiatr Scand. 2014;130(1):61-68. doi:10.1111/acps. 12262

11. Ng AT, Zeller SL, Rhoades RW. Clinical challenges in the pharmacologic management of agitation. Prim Psychiatry. 2010;17(8):46-52.

12. Currier GW, Medori R. Orally versus intramuscularly administered antipsychotic drugs in psychiatric emergencies. $J$ Psychiatr Pract. 2006;12(1):30-40.

13. Citrome L. Inhaled loxapine for agitation revisited: focus on effect sizes from 2 Phase III randomised controlled trials in persons with schizophrenia or bipolar disorder. Int J Clin Pract. 2012;66 (3):318-325. doi:10.1111/j.1742-1241.2011.02890.x

14. Popovic D, Nuss P, Vieta E. Revisiting loxapine: a systematic review. Ann Gen Psychiatry. 2015;14:15-015-0053-3. eCollection 2015. doi:10.1186/s12991-015-0053-3

15. Allen MH, Feifel D, Lesem MD, et al. Efficacy and safety of loxapine for inhalation in the treatment of agitation in patients with schizophrenia: a randomized, double-blind, placebo-controlled trial. J Clin Psychiatry. 2011;72(10):1313-1321. doi:10.4088/JCP.10m06011yel

16. Lesem MD, Tran-Johnson TK, Riesenberg RA, et al. Rapid acute treatment of agitation in individuals with schizophrenia: multicentre, randomised, placebo-controlled study of inhaled loxapine. $\mathrm{Br}$ J Psychiatry. 2011;198(1):51-58. doi:10.1192/bjp.bp.110.081513

17. Kwentus J, Riesenberg RA, Marandi M, et al. Rapid acute treatment of agitation in patients with bipolar I disorder: a multicenter, randomized, placebo-controlled clinical trial with inhaled loxapine. Bipolar Disord. 2012;14(1):31-40. doi:10.1111/ j.1399-5618.2011.00975.x

18. Noymer P, Myers D, Glazer M, et al. The Staccato system: inhaler design characteristics for rapid treatment of CNS disorders. Resp Drug Deliv. 2010;1:11-20.

19. Citrome L. Aerosolised antipsychotic assuages agitation: inhaled loxapine for agitation associated with schizophrenia or bipolar disorder. Int J Clin Pract. 2011;65(3):330-340. doi:10.1111/j.1742-1241.2010.02615.x

20. Spyker DA, Munzar P, Cassella JV. Pharmacokinetics of loxapine following inhalation of a thermally generated aerosol in healthy volunteers. J Clin Pharmacol. 2010;50(2):169-179. doi:10.1177/ 0091270009347866

21. Spyker DA, Voloshko P, Heyman ER, Cassella JV. Loxapine delivered as a thermally generated aerosol does not prolong QTc in a thorough QT/QTe study in healthy subjects. J Clin Pharmacol. 2014;54(6):665-674. doi:10.1002/jcph.257

22. Dinh KV, Myers DJ, Noymer PD, Cassella JV. In vitro aerosol deposition in the oropharyngeal region for Staccato loxapine. J Aerosol Med Pulm Drug Deliv. 2010;23(4):253-260. doi:10.1089/ jamp.2009.0814

23. Currier G, Walsh P. Safety and efficacy review of inhaled loxapine for treatment of agitation. Clin Schizophr Relat Psychoses. 2013;7 (1):25-32. doi:10.3371/CSRP.CUWA.032513

24. Kapur S, Zipursky R, Remington G, Jones C, McKay G, Houle S. PET evidence that loxapine is an equipotent blocker of 5-HT2 and D2 receptors: implications for the therapeutics of schizophrenia. Am J Psychiatry. 1997;154(11):1525-1529. doi:10.1176/ajp.154.11.1525

25. Seeman P. Targeting the dopamine D2 receptor in schizophrenia. Expert Opin Ther Targets. 2006;10(4):515-531. doi:10.1517/ 14728222.10.4.515

26. Singh AN, Barlas C, Singh S, Franks P, Mishra RK. A neurochemical basis for the antipsychotic activity of loxapine: interactions with dopamine D1, D2, D4 and serotonin 5-HT2 receptor subtypes. J Psychiatry Neurosci. 1996;21(1):29-35. 
27. Javitt DC, Duncan L, Balla A, Sershen H. Inhibition of system A-mediated glycine transport in cortical synaptosomes by therapeutic concentrations of clozapine: implications for mechanisms of action. Mol Psychiatry. 2005;10(3):275-287. doi:10.1038/sj.mp.4001552

28. Galen US, Inc. Adasuve (Loxapine Inhalation Powder) Package Insert. Souderton, PA, USA: Galen US, Inc.; 2017.

29. Roth BL, Tandra S, Burgess LH, Sibley DR, Meltzer HY. D4 dopamine receptor binding affinity does not distinguish between typical and atypical antipsychotic drugs. Psychopharmacology (Berl). 1995;120(3):365-368.

30. Chakrabarti A, Bagnall A, Chue P, et al. Loxapine for schizophrenia. Cochrane Database Syst Rev. 2007;4:CD001943. doi:10.1002/ 14651858.CD001943.pub2

31. de Berardis D, Fornaro M, Orsolini L, et al. The role of inhaled loxapine in the treatment of acute agitation in patients with psychiatric disorders: a clinical review. Int J Mol Sci. 2017;18(2). doi:10.3390/ijms18020349

32. Meltzer HY, Matsubara S, Lee JC. The ratios of serotonin2 and dopamine2 affinities differentiate atypical and typical antipsychotic drugs. Psychopharmacol Bull. 1989;25(3):390-392.

33. Stockmeier CA, DiCarlo JJ, Zhang Y, Thompson P, Meltzer HY. Characterization of typical and atypical antipsychotic drugs based on in vivo occupancy of serotonin2 and dopamine2 receptors. J Pharmacol Exp Ther. 1993;266(3):1374-1384.

34. Midha KK, Hubbard JW, McKay G, Hawes EM, Hsia D. The role of metabolites in a bioequivalence study 1: loxapine, 7-hydroxyloxapine and 8-hydroxyloxapine. Int J Clin Pharmacol Ther Toxicol. 1993;31 (4):177-183.

35. Wong YC, Zuo Z. Brain disposition and catalepsy after intranasal delivery of loxapine: role of metabolism in PK/PD of intranasal CNS drugs. Pharm Res. 2013;30(9):2368-2384. doi:10.1007/s11095-013-1080-X

36. Zeller S, Zun L, Cassella JV, Spyker DA, Yeung PP. Response to inhaled loxapine in patients with schizophrenia or bipolar I disorder: PANSS-EC responder analyses. BJ Psych Open. 2017;3(6):285-290. doi:10.1192/bjpo.bp.117.005363

37. Citrome L. Comparison of intramuscular ziprasidone, olanzapine, or aripiprazole for agitation: a quantitative review of efficacy and safety. J Clin Psychiatry. 2007;68(12):1876-1885.

38. San L, Estrada G, Oudovenko N, et al. PLACID study: a randomized trial comparing the efficacy and safety of inhaled loxapine versus intramuscular aripiprazole in acutely agitated patients with schizophrenia or bipolar disorder. Eur Neuropsychopharmacol. 2018;28 (6):710-718. doi:10.1016/j.euroneuro.2018.03.010
39. McDowell M, Nitti K, Kulstad E, et al. Clinical outcomes in patients taking inhaled loxapine, haloperidol, or ziprasidone in the emergency department. Clin Neuropharmacol. 2019. doi:10.1097/WNF.000000 0000000325

40. Cassella JV, Spyker DA, Yeung PP. A randomized, placebo-controlled repeat-dose thorough QT study of inhaled loxapine in healthy volunteers. Int $J$ Clin Pharmacol Ther. 2015;53:963-971. doi:10.5414/CP202457

41. Gross N, Greos LS, Meltzer EO, et al. Safety and tolerability of inhaled loxapine in subjects with asthma and chronic obstructive pulmonary disease-two randomized controlled trials. J Aerosol Med Pulm Drug Deliv. 2014;27(6):478-487. doi:10.1089/jamp.2013.1114

42. Roberts J, Gracia Canales A, Blanthorn-Hazell S, Craciun Boldeanu A, Judge D. Characterizing the experience of agitation in patients with bipolar disorder and schizophrenia. BMC Psychiatry. 2018;18(1):104-018-1673-3. doi:10.1186/s12888-018-1673-3

43. Atkinson MJ, Sinha A, Hass SL, et al. Validation of a general measure of treatment satisfaction, the Treatment Satisfaction Questionnaire for Medication (TSQM), using a national panel study of chronic disease. Health Qual Life Outcomes. 2004;2:12-75252-12. doi:10.1186/1477-7525-2-12

44. Jorgensen TR, Emborg C, Dahlen K, Bogelund M, Carlborg A. The effect of the medicine administration route on health-related quality of life: results from a time trade-off survey in patients with bipolar disorder or schizophrenia in 2 Nordic countries. BMC Psychiatry. 2016;16:244-016-0930-6. doi:10.1186/s12888-016-0930-6

45. Kahl KG, Negt P, Wollmer A, Jung S, Kruger TH. Inhaled loxapine for acute treatment of agitation in patients with borderline personality disorder: a case series. J Clin Psychopharmacol. 2015;35 (6):741-743. doi:10.1097/JCP.0000000000000402

46. Roncero C, Ros-Cucurull E, Grau-Lopez L, Fadeuilhe C, Casas M. Effectiveness of Inhaled Loxapine in dual-diagnosis patients: a case series. Clin Neuropharmacol. 2016;39(4):206-209. doi:10.1097/ WNF.0000000000000153

47. Sztrymf B, Chevrel G, Bertrand F, et al. Beneficial effects of loxapine on agitation and breathing patterns during weaning from mechanical ventilation. Crit Care. 2010;14(3):R86. doi:10.1186/cc9015

48. Jaffe R, Siniscalchi M, Cruz-Luna N, Cosgrove D. Inhaled loxapine for ECT pretreatment for agitation. $J$ Ect. 2016;32(2):146. doi:10.1097/YCT.0000000000000276

49. Selim S, Riesenberg R, Cassella J, et al. Pharmacokinetics and safety of single-dose inhaled loxapine in children and adolescents. J Clin Pharmacol. 2017;57(10):1244-1257. doi:10.1002/jcph.932
Neuropsychiatric Disease and Treatment

\section{Publish your work in this journal}

Neuropsychiatric Disease and Treatment is an international, peerreviewed journal of clinical therapeutics and pharmacology focusing on concise rapid reporting of clinical or pre-clinical studies on a range of neuropsychiatric and neurological disorders. This journal is indexed on PubMed Central, the 'PsycINFO' database and CAS, and is the official journal of The International Neuropsychiatric Association (INA). The manuscript management system is completely online and includes a very quick and fair peer-review system, which is all easy to use. Visit http://www.dovepress.com/testimonials.php to read real quotes from published authors. 